\title{
Student Performance in First Year, Mathematics, and Physics Courses: Implications for Success in the Study of Electrical and Computer Engineering
}

\author{
Jane Simpson, Dr. Eugenia Fernandez \\ Indiana University-Purdue University (IUPUI) \\ Indianapolis, IN
}

\begin{abstract}
Mathematics and physics courses are recognized as a crucial foundation for the study of engineering, and often are prerequisite courses for the basic engineering curriculum. But how does performance in these prerequisite courses affect student performance in engineering courses? This study evaluated the relationship between grades in prerequisite math and physics courses and grades in subsequent electrical engineering courses. Where significant relationships were found, additional analysis was conducted to determine minimum grade goals for the prerequisite courses. Relationships were found between five course pairs: calculus II and differential equations; calculus II and physics I (mechanics); physics II (electricity and optics) and circuits analysis II; physics II (electricity and optics) and signals and systems; and circuits analysis II and signals and systems. The results indicate that a grade of $\mathrm{C}+$ or higher in calculus II, and a grade of B- or higher in physics II and circuits analysis II will lead to higher grades in subsequent mathematics, circuits, and signals and systems courses. This information will be used to aid faculty in making decisions about imposing minimum grade requirements.
\end{abstract}

Keywords-freshman engineering, prerequisite courses, grades

\section{INTRODUCTION}

Indiana University-Purdue University Indianapolis (IUPUI) is an urban research university with approximately 30,000 students, more than 2,400 in the School of Engineering and Technology (E\&T). There are 280 undergraduate students in the Department of Electrical and Computer Engineering (ECE).

Engineering courses rely heavily on problem solving skills using math and physics. Undergraduate students in ECE at IUPUI are required to take 18 credit hours of mathematics and nine credit hours of physics during their freshman and sophomore years to develop these skills. The classes are preor co-requisites for basic engineering courses, and the skills learned are used throughout the engineering curriculum. This study was conducted to determine what effect, if any, the grades in these prerequisite courses have on students' grades in later courses.

Current degree requirements for the students do not include minimum grades for most of the math and physics classes. The Department of Mathematics at IUPUI has imposed minimum grade requirements for the two lowest-level math courses. A grade of D- will satisfy degree requirements in the five remaining math and physics classes. The ECE faculty has expressed concern about students' knowledge of math and physics, questioning the impact of poor performance in those subjects on success in subsequent engineering courses, and on the ability of students to graduate on time.

The current emphasis placed on both graduation rates and quality education by the Indiana Commission for Higher Education makes these questions especially timely [1]. Researching the questions will aid ECE's efforts to improve student learning and graduation rates. Focusing resources on improved performance in lower-level and core courses could result in improved graduation rates and higher academic achievement.

\section{LITERATURE REVIEW}

Mathematics and physics are important skills in engineering, and grades in those subjects have been considered to be good indicators for student success in engineering studies. In a study of the first-year progress of engineering students, van der Hulst and Jansen found that the physics and math final exam grades of secondary school students were predictors of the students' progress, as measured by credits earned [2]. Similarly, Tyson examined high school accelerated physics and calculus grades' influence on grades earned in college math and physics courses of engineering students, and found that high school calculus performance was the best predictor of grades in college physics and college courses [3]. Neither commented on the scores received by the engineering students in first-year studies. Conversely, Mesa, Jaquette and Finelli tested whether enrollment in a second semester honors calculus course had an impact on subsequent performance for engineering students [4]. It did not, although the results were probably affected by the fact that their sample consisted of students who had all placed out of the first-semester calculus course.

In a study at Texas State University-San Marcos, Easter found that students' GPAs and Chemistry One grades were significant indicators of students' grades in Chemistry Two [5]. When the School of Science and the College of Engineering at Louisiana Tech University merged, reorganized, and integrated

This is the author's manuscript of the article published in final edited form as:

Simpson, J., \& Fernandez, E. (2014). Student performance in first year, mathematics, and physics courses: Implications for success in the study of electrical and computer engineering. In 2014 IEEE Frontiers in Education Conference (FIE) (pp. 1-4). http://doi.org/10.1109/FIE.2014.7044368 
curriculum, Benedict, Napper, and Guice reported a percentage increase in students that received an $\mathrm{A}, \mathrm{B}$, or $\mathrm{C}$ in early calculus and physics courses [6]. They also report preliminary findings indicative of improved student retention and time to degree completion, but no conclusions as to whether this is the result of improved performance in mathematics and physics or if it is the result of other curriculum changes made to higher level courses.

In a study of prerequisite relationships between courses in computer programming and other related areas, Hwang, $\mathrm{Yu}$, $\mathrm{Su}$, and Tseng used fuzzy sets of low, medium, and high grades to analyze significant correlations [7]. Expected correlations between high, medium, and low grades in pairs of programming courses were confirmed, similar to the relationships expected between successive math courses in the engineering curriculum. While the study did not encompass specific grade requirements, it did serve as a tool for identifying requisite course pairs that should be revisited due to unexpected negative correlations.

The question of minimum grade goals coupled with students' capacity for self-control was studied by Bertrams [8]. The study used grade goals set by the individual students rather than minimum grade requirements imposed by the faculty. The self-control element of his research considered beginning a task such as studying, and resisting distractions during a task. He reported higher minimum grade goals for a test predicted higher test grades, regardless of the students' levels of selfcontrol. Minimum grade goals imposed by curriculum requirements were considered by Potolsky, Cohen, and Saylor who found that nursing students with higher grades in prerequisite science courses also received higher grades in the subsequent nursing courses [9]. They suggested a minimum GPA of B in the prerequisite courses as a group, as a way to increase student persistence to degree completion and to increase academic performance.

This study focuses on examining the relationship between prerequisite math and physics courses and subsequent electrical engineering courses. Where relationships are found, minimum grade goals are determined for the prerequisite courses.

\section{Methods}

This study examined data about current and former undergraduate students in the ECE to determine if any correlations exist between a student's early grades, and his or her grades in low- to mid-level engineering courses. It was hypothesized that positive correlations exist between each pair of prerequisite and subsequent courses.

The population of students in the study was the 53 undergraduate students who entered the school in the fall semesters of 2008 and 2009 majoring in electrical engineering or computer engineering. The majority of the students were male, and were traditional college aged first-time students.

Course grades in targeted courses were retrieved for all students. These include courses in the freshman curriculum and ECE core courses and other prerequisites to those courses. After retrieval of data, the results from all sources were compiled, and all identifying information was removed.
Grades in the classes were reported as letter grades. For analysis, the grades were assigned an equivalent point value (Table 1).

TABLE I. POINTS ASSIGNED TO LETTER GRADES

\begin{tabular}{|c|c|c|c|c|c|}
\hline Grade & Points & Grade & Points & Grade & Points \\
\hline $\mathrm{A}+$ & 4.0 & B- & 2.7 & $\mathrm{D}$ & 1.0 \\
\hline $\mathrm{A}$ & 4.0 & $\mathrm{C}+$ & 2.3 & D- & 0.7 \\
\hline A- & 3.7 & $\mathrm{C}$ & 2.0 & $\mathrm{~F}$ & 0 \\
\hline $\mathrm{B}+$ & 3.3 & C- & 1.7 & & \\
\hline B & 3.0 & $\mathrm{D}+$ & 1.3 & & \\
\hline
\end{tabular}

Fig. 1 shows pre- and co-requisite relationships for the courses considered in this study. Prerequisites are indicated by a solid arrow. Co-requisites are indicated by a dashed arrow.

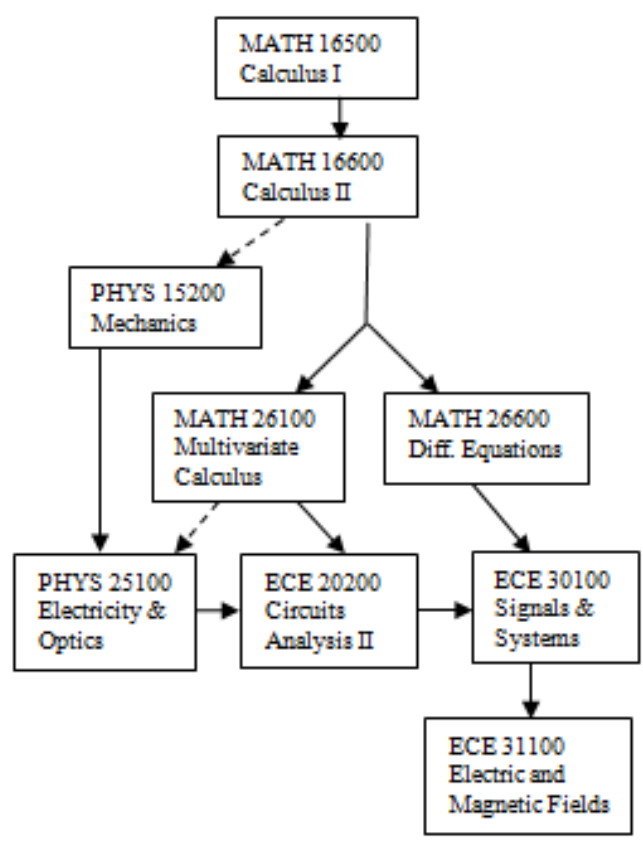

Fig. 1. Course requisites

Descriptive statistical analysis of the course grades was conducted, with the results shown in Table 2. Because the mean was so close to the maximum (4.0) for freshman engineering and communication courses (shown in italics), those courses were not included in further analysis.

\section{RESULTS}

Simple linear regression was calculated to determine if relationships exist between the grades received by students in math and physics courses, and the grades received by the same students in core engineering courses. Significant relationships were found in six cases (Table 3 ). 
TABLE II. DESCRIPTIVE STATISTICS FOR COURSE GRADES

\begin{tabular}{|l|c|c|c|c|}
\hline \multicolumn{1}{|c|}{ Course } & N & Mean & $\begin{array}{c}\text { Std. } \\
\text { Deviation }\end{array}$ & $\begin{array}{c}\text { Used in } \\
\text { Further } \\
\text { Analysis }\end{array}$ \\
\hline ENGR 19500 & 34 & 3.92 & 0.256 & No \\
\hline ENGR 19600 & 37 & 3.73 & 0.427 & No \\
\hline ENG-W 131 & 36 & 3.50 & 0.591 & No \\
\hline COMM-R 110 & 37 & 3.43 & 0.598 & No \\
\hline ECE 20200 & 26 & 3.02 & 0.871 & Yes \\
\hline MATH 26600 & 29 & 2.87 & 0.96 & Yes \\
\hline ECE 30100 & 24 & 2.85 & 0.837 & Yes \\
\hline MATH 16500 & 33 & 2.77 & 0.712 & Yes \\
\hline MATH 16600 & 32 & 2.73 & 0.904 & Yes \\
\hline PHYS 25100 & 30 & 2.69 & 0.753 & Yes \\
\hline PHYS 15200 & 35 & 2.65 & 1.112 & Yes \\
\hline ECE 31100 & 15 & 2.54 & 1.015 & Yes \\
\hline MATH 26100 & 31 & 2.43 & 0.907 & Yes \\
\hline
\end{tabular}

Further analysis was conducted on five pairs of courses with significant relationships between grades, shown in bold in Table 3, to determine minimum grade goals for the prerequisite course. Math 26100 and Phys 25100 were not included as these courses are co-requisites. To determine the prerequisite
TABLE IV. PREREQUisite GRAdE GoAls

\begin{tabular}{|c|c|c|c|c|c|}
\hline $\begin{array}{c}\text { Prerequisite } \\
\text { Course }\end{array}$ & $\begin{array}{c}\text { Subsequent } \\
\text { Course }\end{array}$ & $\begin{array}{c}\text { Prereq. } \\
\text { Group } \\
\text { Values }\end{array}$ & $\mathbf{N}$ & Mean & $p$ \\
\hline \multirow{2}{*}{ Math 16600} & \multirow{2}{*}{ Math 26600} & $<\mathrm{C}+$ & 9 & 2.33 & \multirow{2}{*}{.004} \\
\hline & & $\geq \mathrm{C}+$ & 17 & 3.28 & \\
\hline \multirow{2}{*}{ Phys 25100} & \multirow{2}{*}{ ECE 20200} & $<\mathrm{B}$ & 10 & 2.42 & \multirow{2}{*}{.0045} \\
\hline & & $\geq \mathrm{B}$ & 14 & 3.31 & \\
\hline \multirow{2}{*}{ Phys 25100} & \multirow{2}{*}{ ECE 30100} & $<\mathrm{B}$ & 9 & 2.30 & \multirow{2}{*}{.0075} \\
\hline & & $\geq \mathrm{B}$ & 14 & 3.12 & \\
\hline \multirow{2}{*}{ ECE 20200} & \multirow{2}{*}{ ECE 30100} & $<\mathrm{B}$ & 5 & 1.94 & \multirow{2}{*}{.002} \\
\hline & & $\geq \mathrm{B}-$ & 19 & 3.09 & \\
\hline
\end{tabular}

grade goals, a series of independent one-tailed t-tests were conducted. Grades in the prerequisite courses were used to create two groups, and these groups were used in the independent t-test to determine if there was significant difference in subsequent course grade between the two groups. A grade of B- (2.7) was used as the initial group cutoff. If no significant difference was found, the test was repeated with a grade of $\mathrm{C}+(2.3)$. Table 4 shows results of the t-tests where significant differences were found.

TABLE III. RESULTS OF LINEAR REGRESSION ANALYSIS

\begin{tabular}{|c|c|c|c|c|c|c|}
\hline $\begin{array}{l}\text { Prerequisite } \\
\text { Course (x) }\end{array}$ & $\begin{array}{l}\text { Subsequent } \\
\text { Course (y) }\end{array}$ & $\mathbf{R}^{2}$ & df & $\boldsymbol{F}$ & $p$ & $\begin{array}{l}\text { Regression Equation } \\
\text { (if significant) }\end{array}$ \\
\hline Math 16600 & Math 26600 & 0.254 & 24 & 8.19 & 0.009 & $y=1.325+.587(x)$ \\
\hline Math 16600 & Phys 15200 & 0.131 & 29 & 4.37 & 0.045 & $y=1.692+.388(x)$ \\
\hline Math 26100 & Phys 25100 & 0.332 & 27 & 13.4 & 0.001 & $y=1.563+.447(x)$ \\
\hline Phys 25100 & ECE 20200 & 0.375 & 22 & 13.2 & 0.001 & $y=0.992+.685(x)$ \\
\hline Phys 25100 & ECE 30100 & 0.221 & 21 & 5.97 & 0.024 & $y=1.345+.506(x)$ \\
\hline ECE 20200 & ECE 30100 & 0.391 & 22 & 14.1 & 0.001 & $y=0.213+.849(x)$ \\
\hline Phys 25100 & ECE 31100 & 0.161 & 9 & 1.72 & 0.222 & \\
\hline Math 16500 & Math 16600 & 0.073 & 25 & 1.97 & 0.173 & \\
\hline Math 16600 & Math 26100 & 0.036 & 26 & 0.97 & 0.335 & \\
\hline Math 26100 & ECE 20200 & 0.087 & 22 & 2.09 & 0.162 & \\
\hline Math 26100 & ECE 30100 & 0.069 & 20 & 1.49 & 0.237 & \\
\hline Math 26100 & ECE 31100 & 0.139 & 8 & 1.29 & 0.289 & \\
\hline Math 26600 & ECE 30100 & 0.003 & 21 & 0.06 & 0.812 & \\
\hline Math 26600 & ECE 31100 & 0.005 & 9 & 0.049 & 0.829 & \\
\hline
\end{tabular}




\section{DISCUSSION}

The linear regression analysis showed a positive correlation between grades in some math and physics classes and grades in two engineering classes. The relationship between Math 16600 and Math 26600 can be explained by the implementation in 2012 of an automatic withdrawal policy for students that did not earn a minimum grade of $\mathrm{C}$ in Math 16600 before enrolling in Math 26600. The t-test shows that a grade of at least $\mathrm{C}+$ in Math 16600 could result in an increase of nearly one full letter grade in Math 26600. The relationship between Math 16600 and Phys 15200 helps to underscore the importance of the calculus class for physics, as does the correlation between Math 26100 and Phys 25100.

The relationships between Phys 25100, ECE 20200, and ECE 30100 were expected as Phys 25100 is a prerequisite for ECE 20200 which, in turn, is a prerequisite for ECE 30100. The t-tests performed on these courses showed that students with a minimum grade of B- in the prerequisite courses had a mean grade of B or higher in the post-requisite courses, while those students with grades lower than B- earned mean grades of $\mathrm{C}+$ or lower. The students earning lower than B- in ECE 20200 did very poorly, with a mean of 1.94 in ECE $30100-a$ grade lower than a $\mathrm{C}$.

No significant relationship was found between Phys 25100 and ECE 31100. Because both of those classes had magnetics as a subject, a correlation had been expected. The low number of cases with grades for both classes might have affected this outcome. Surprisingly, no significant relationship was found between second level math courses and ECE courses. This may be due to the indirect prerequisite structure or the low number of cases.

\section{CONCLUSION}

Significant relationships were found between some math and science courses and ECE courses. These findings are in line with those of Easter [5] and Potolsky, Cohen, and Saylor [9] who found that grades in prerequisite courses were indicators of grades in subsequent courses. Not surprising, students who earned high grades in the prerequisite classes received higher grades in the subsequent courses as well.

The relationships found are heartening as they lend support for having the prerequisite requirement and highlight the importance of the prerequisite courses. This has implications for the students, faculty, and curriculum. Students and instructors should be made aware of the impact that performance in the prerequisite course may have, and resources for both groups increased. For example, tutoring and creation of study groups may benefit the students as would more teaching support for the instructor.

On the curricular level, these results can support requests for changes in minimum grade requirements in prerequisite courses for Math 26600, Phys 25100, ECE 20200, and ECE 30100. The results of this study can also be used to inform those who design the undergraduate curriculum in their decisions about changing prerequisites for courses in the major, and suggest what minimum grades should be used. The results also highlight the fact that most students receive very high grades in freshman engineering and communications courses. So, while low grades in such courses may be an indication of lack of effort or difficulties adjusting to college-level study, high grades do not necessarily indicate that a student is prepared to move into the core engineering curriculum.

Additional studies including a larger sample population and considering relationships involving more core engineering courses would be helpful to refine the curriculum requirements.

Questions arise when looking at the course pairs in which significant relationships were not found. While a contributing factor may have been the low numbers of students in the courses, it suggests that what may be needed is an examination of the content and/or approach to the curriculum in these courses.

While these results are not generalizable to other engineering disciplines or schools, it provides an example of a method of analysis that can be replicated at other institutions.

\section{REFERENCES}

[1] Indiana Commission for Higher Education. 2012. Reaching Higher, Achieving More. http://www.in.gov/che/files/2012_RHAM_8_23_12.pdf. Accessed: 1 January 2014

[2] van der Hulst, M., and E. Jansen. 2002. "Effects of Curriculum Organization on Study Progress in Engineering Studies." Higher Education. Vol. 43 (4), pp. 489-506.

[3] Tyson, W. 2011. "Modeling Engineerng Degree Attainment Using High School and College Physics and Calculus Coursetaking and Achievement." Journal of Engineering Education. Vol. 100 (4), p. 760777 .

[4] Mesa, V., O. Jaquette and C.J. Finelli. 2009. "Measuring the Impact of an Individual Course on Students' Success." Journal of Engineering Education. Vol 98 (4), p. 349-359.

[5] Easter, D. C. 2010. "Factors Influencing Student Prerequisite Preparation for and Subsequent Performance in College Chemistry Two: A Statistical Investigation." Journal of Chemical Education. Vol. 87 (5), pp. 535-540.

[6] Benedict, B. A., Napper, S. A., and Guice, L. K. 2000. "Restructuring for Strategic Outcomes." Journal Of Engineering Education. Vol. 89 (2), pp. 237-246.

[7] Hwang, C.-S., P. Yu, Y-C. Su, and K.C.Tseng. 2009. "Validation of Course Prerequisites Based on Student Grade Using Fuzzy Association Rules.” Management and Service Science, 2009. MASS 09. International Conference on, pp. 1-3. Doi 10.1109/ICMSS.2009.5302781

[8] Bertrams, A. 2012. "How Minimal Grade Goals and Self-control Capacity Interact in Predicting Test Grades." Learning and Individual Differences. Vol. 22 (6), pp. 833-838.

[9] Potolsky, A., Cohen, J., and Saylor, C. 2003. "Academic Performance of Nursing Students: Do Prerequisite Grades and Tutoring Make a Difference?" Nursing Education Perspectives. Vol. 24 (5), pp. 246-250. 